\title{
Research on Generation Enterprises Marketing Management System in the Environment of Sale Market Opening
}

\author{
Jiwen $\mathrm{Li}^{1, \mathrm{a}}$, Zhen $\mathrm{Xu}^{2}$, Zhenhe Dong ${ }^{1}$, Xiaofeng $\mathrm{Yu}^{1}$ \\ ${ }^{1}$ Huadian Power International Corporation Limited ShanDong Branch 250014, China \\ ${ }^{2}$ ShanDong Province Electrical Enterprise Association 250101, China \\ a1365562235@qq.com
}

Keywords: Sale market opening, Power plant electricity sales, marketing management system

\begin{abstract}
With the sale market opening, generation schedule will gradually open up, genertation enterprise convert it's role from passive acceptance of traditional power plant dispatching instruction execution role into independent role in sale market. Generation enterprise can also set up sales company, start electricity sales business. In order to adapt to this converse, this paper starts from the research on grid dispatching mechanism, analyse the contracts signed by power plants and users, set up the indicator of diapaching management from the perspective of power plant management, and design the new function of dispatching management system of generation enterprise, and the related management suggestiongs are given.
\end{abstract}

\section{Introduction}

In conventional planning management of power system operation mode, and grid enterprise shoulder the responsibility of stability and economic dispatching ${ }^{[1]}$. In a separate gird region, Grid enterprise are generally equipped with control center, which be responsible for the regional power grid control. But the grid enterprise's control, is unable to play a role of optimizing the allocation of resources in the electricity market very well ${ }^{[2]}$. On the contary, the efficiency of the electricity market is relatively high, so many countries are exploring the opening of electricity market ${ }^{[3]}$, As far as market forces, it can improve the economy of electric power system a lot.

In the environment of electricity market opening, Generation enterprise can signe contracts with users or an electricity retailer directly, contract electric quantity and real-time balance are two key elements. This paper will draw on international electricity market and open market mechanism design and the traditional power grid company's dispatch system and research the electricity market electricity sales business of dispatching management system in thermal power plant under the circumstances of opening up.

\section{Study on the index system for power grid dispatching}

Traditional uniform dispatching system for grid enterprises, power plant dispatching is based on power grid enterprise dispatching instructions and generation plan. Generally transmission preparation of generation scheduling in the following basis ${ }^{[4]}$ :

( 1 ) Load forecasting;

( 2 ) Capacity and maintenance of power equipment;

( 3 ) For load flow, stability, regulating and economic requirements;

( 4 ) pool purchase price;

( 5 ) The power purchase and sale contracts;

( 6 ) Coal-fired thermal power plant storage;

( 7 ) Situation of water resources in hydroelectric power plant, on comprehensive benefit of hydro power plant reservoir, according to Hydro design papers approved, taking into account areas such as flood control, irrigation, power generation, environmental protection requirements, the rational use of reservoir;

( 8 ) Delivery (purchase) plans; 
( 9 ) Report generation scheduling in power plant;

( 10 ) The grid dispatching contract.

In the process of liberalization of Electricity sale market, the government departments will promote the information about power grid including transmission capacity and the key sispatching such as available capacity, power plant dispatching will gradually be strengthened ${ }^{[5,6]}$. Therefore, on the one hand, the power plant dispatching information collected needs to be strengthened and management, on the other hand need to learn power grid dispatching mechanism, train dispatchers.

\section{The key indicators of generation enterprise marketing research and management}

\section{( 1 ) Electric quantity plans}

Electric quantity plans can be divided into: super short, short, medium and long term, very short term refers to real-time generation control, their action cycle is always seconds or minutes-; short term plan refers to the daily or weekly plan; medium-term are the plans and correction of months to years, including : Load forecasting, water, maintenance planning, reservoir operation plan, fuel and exchange program; long-term planning refers to the number of years to decades of planning, including power development planning and network development planning, short-term generation scheduling include: thermal power plans, unit mix, water and electricity plan, Exchange programs, such as fuel and maintenance schedules. As far as the power system dominated by thermal power generation, thermal power generation is the core of the whole generation, mainly due to thermal power is the power output of the main. According to the actual situation, electricity planning refers to the traditional coal-fired power unit power plan.

Generation enterprise trading with users directly, produce extra electricity power plans, this part is unprecedented, and the contract is main source of power generation enterprise quantity plans. In General, if power plants are unable to complete the contract,the plants need to buy power at for making up for the users. If one user cannot finish a contract charge, for power generation enterprise, and generating capacity is wasted, so electric quantity plans is critical.

Sale market opening is expected to refer to the generate electricity company deals directly with the user experience, and according to the daily power curve, real-time balance management, power plant and purchasing power in the main power supply contract signed is very important indicator. So electric quantity plans in power enterprises in production management position will be further enhanced.

So the generation enterprise should set electric quantity management warning system, specific thought is set a warning index, for power user contract power in agreed period within consumption too less of case, generation enterprise should understand customer of actual needs, transfer consumption of power timely, cannot idle resources; for power user in agreed period within power consumption too more of case, to full understand itself of production capacity, manage the production capacity sufficient, give suggestiong to user and recommend the user signe new contract; For its own production capacity during the agreed period are not available to power users, generation enterprises should seek other electricity market which has the excess power generation power plant, transfer its power supply contract.

( 2 ) Loading rate

In the management of thermal power, loading rate refers to a reporting period of the average load and peak-load ratio to account for differences in load levels. Larger loading tate shows that balanced production, equipment utilization levels is high. Loading rate is the enterprise's power-generation capacity of rational use of key indicators, the calculation formula is as (3.1) below:

$$
\text { Loading rate }=\frac{\text { average load in reporting pertod }}{\text { peak-ioad in reporting pertod }}
$$

According to the electric power market development, combined with the current study on the planning of new trends in the development of China's power market,the future electricity market is mainly composed of medium-and long-term market and two parts to the spot market. Medium-and 
long-term market is seted up for years, years, seasons, months, weeks, days or more. The spot market will mainly carry out a day-ahead trading, day trading, spot energy trading and alternative , frequency control services and so on.

As the power sale markets opening, power companies can effectively grasp the market trends and the short-term market trends, full generation capacity are key elements of enterprise can gain excellent benefits.

\section{Research on Power generation enterprise marketing management system}

In order to achieve the effective management of the productive capacity and flexibility to react to market changes, power marketing management system need to be established, the system's structure is as follows:

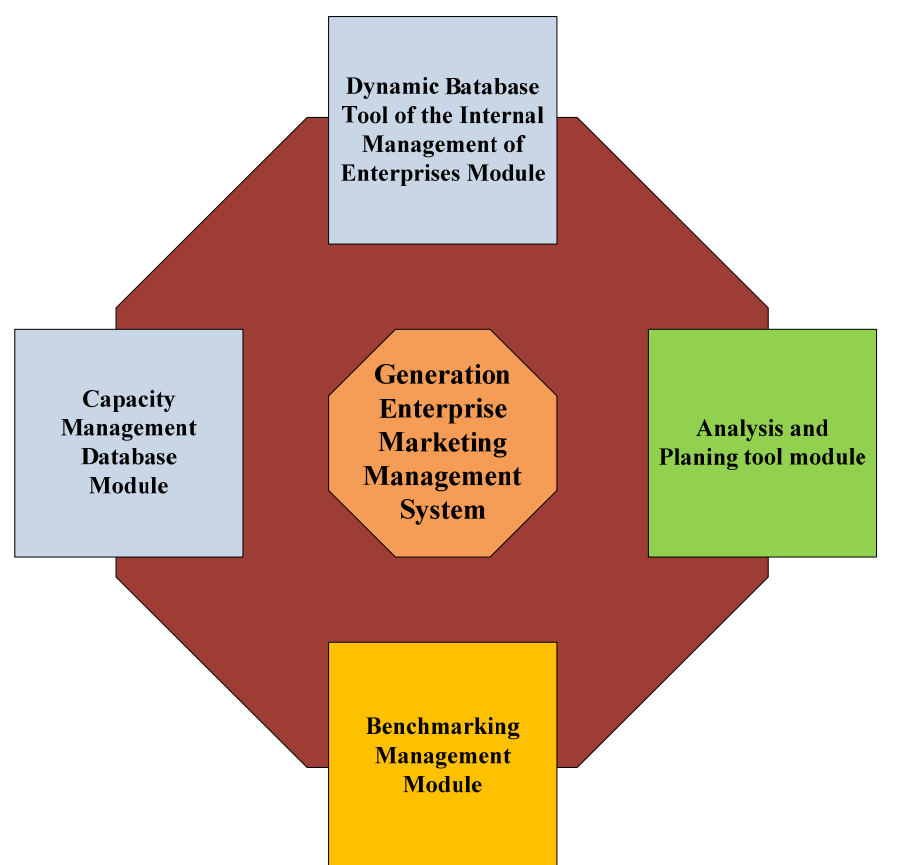

Fig 3.1 The structrue of generation enterprise marketing management.

( 1 ) Dynamic Database Tool of the Internal Management of Enterprises Module

Established capacity management database, the database contains basic information of unit, annual electricity plan, implementation, annual maintenance plan and market plans; completion of days, months, years, power units (so) repair, fuel procurement (quality, quantity and price) and reserves (in days), and other important information.

( 2 ) Capacity Management Database Module

It is necessary to establish an internal dynamic analysis tool, the tool should have an intuitive ability to reflect the information contained in the module database, and can be easily added and deleted data, in addition, should also have some data analysis, summarize the results of analysis of information, provide reference for decision-making.

( 3 ) Analysis and Planing tool module

Planned power analysis of the amount of remaining scheduled electric power, as the company's electricity sales of traffic based on load ratio designed to improved unit utilization in a competitive environment for the company to create more opportunities.

( 4 ) Benchmarking Management Module

Power plant electricity sales business, and to apply the benchmarking, which mainly involves three aspects: production of electrical energy benchmarking, dispatch, customer experience, benchmarking, as Figure 3.1 shows.

Benchmarking should first establish the benchmarking indicators. In electricity production of standard parts, thermal power plants generally have accumulated a wealth of experience in benchmarking and will not repeat them here. 
Electric quantity management is an important functions of generation enterprises. With the advancement of electricity market reform, the direct deal electric quantity will expand a lot, independent dispatching of power generation enterprises have grown in importance, therefore needs to be applied to management methods to strengthen schedules management.

Customer experience benchmarking management methods that is seldom used, because in the former State monopoly of power system, power generation enterprise customers is just the grid, until power plants after the release directly with the user, customer diversification, with increasingly more open electricity market, customers will become more and more abundant, good user experience is the focus of marketing ${ }^{[14]}$. Therefore genertation enterprise need to be applied to management methods, improving customer experience, and expand market share.

\section{Summary}

As sale market opening, generation enterprise participationr market trading can get more profits than sale electricity to grid enterprise. In face sale market opening, generation enterprise should active immediately, strengthening on the training of dispatching personnel, reform the internal management system, established a flexible linkage mechanism between marketing and production, improve service level fully, reduced generation cost, constantly expanded the share of market.

\section{Acknowledgement}

This article is supported by the project which is named "research on the marketing management strategy of power enterprises to deal with the electricity side reform" of Huadian Power International Corporation Limited ShanDong Branch.

\section{Reference}

[1] Xiaokun Chang, Ming Dong, Dong Yang. Multi-objective real-time dispatching for integrated delivery in a Fab using GA based simulation optimization[J]. Journal of Manufacturing Systems, 2013, 32(4):741-751.

[2] Mohsen Gitizadeh, Hamid Fakharzadegan. Battery capacity determination with respect to optimized energy dispatch schedule in grid-connected photovoltaic (PV) systems[J]. Energy, 2013, 65:665-674.

[3] Ranjit Roy, S.P. Ghoshal. A novel crazy swarm optimized economic load dispatch for various types of cost functions[J]. International Journal of Electrical Power and Energy Systems, 2007, 30(4):242-253.

[4] Stjepan Sučić, Tomislav Dragičević, Tomislav Capuder, Marko Delimar. Economic dispatch of virtual power plants in an event-driven service-oriented framework using standards-based communications[J]. Electric Power Systems Research, 2011, 81(12):2108-2119.

[5] Jordan Wilkerson, Peter Larsen, Galen Barbose. Survey of Western U.S. electric utility resource plans[J]. Energy Policy, 2013, 66:90-103.

[6] Robin Roche, Lhassane Idoumghar, Siddharth Suryanarayanan, et al. A flexible and efficient multi-agent gas turbine power plant energy management system with economic and environmental constraints[J]. Applied Energy, 2013,101:644-654. 